The Need for Inclusion: The Relationships between Relational and Collective Inclusion Needs and Psychological Well- and Ill-Being

Barbara Valcke ${ }^{1}$, Alain Van Hiel ${ }^{1}$, Jasper Van Assche ${ }^{1}$, Thomas Van Roey ${ }^{2}$, Emma Onraet ${ }^{1}, \&$ Arne Roets ${ }^{1}$

${ }^{l}$ Department of Developmental, Personality and Social Psychology, Ghent University ${ }^{2}$ Department of Sociology, Ghent University

Correspondence should be addressed to Barbara Valcke, Department of Developmental, Personality and Social Psychology, Henri Dunantlaan 2, B-9000, Ghent, Belgium. barbara.valcke@Ugent.be

Author note: The authors declare that there are no potential conflicts of interest with respect to the research, authorship, and/or publication of this article

Word count: 10.025

\title{
Ethics statements
}

This article has been accepted for publication and undergone full peer review but has not been through the copyediting, typesetting, pagination and proofreading process, which may lead to differences between this version and the Version of Record. Please cite this article as doi: 10.1002/EJSP.2641

This article is protected by copyright. All rights reserved 
This study was carried out in accordance with the recommendations and approved by the Research Ethics Committee of the Faculty of Psychology and Educational Sciences of Ghent University.

Respondents on Prolific Academic agreed with an informed consent before starting the survey, in which we stated that all the information they provided during the study will be treated confidentially, and the results of our study would only be used for research purposes. By clicking "I agree" they indicated that they were at least 18 years old, have read and understood the consent form and agreed to participate in this research study. We provided our contact information in case of any questions or comments. Respondents also agreed with the PARTICIPATION AGREEMENT of Prolific Academic.

\section{Data sharing}

All data files are openly available on https://osf.io/ztwc6/ 
MISS BARBARA VALCKE (Orcid ID : 0000-0001-6353-8308)

MR. JASPER VAN ASSCHE (Orcid ID : 0000-0002-2570-2928)

Article type : Research Article

\section{Abstract}

The Need to Belong concept encompasses the need for inclusion and the discomfort with exclusion. The Need to Belong Scale of Leary, Kelly, Cottrell, and Schreindorfer (2013), however, primarily probes into the discomfort aspect, and it does not distinguish between relational and collective self-levels. Two studies (total $N=429$ ) provided evidence of the reliability, distinctiveness and validity of the newly developed Need for Inclusion scale. The results revealed that Relational Need for Inclusion positively contributes to psychological well-being and negatively to ill-being. Collective Need for Inclusion was distinctively related to collective and group-level outcomes of self, such as social trust and collective self-esteem. Need to Belong yielded a reversed pattern of results for the studied outcomes. It is concluded that inclusion needs and discomfort with exclusion are positively related but clearly distinct, and that future studies should investigate their joint effects in a single research design.

Keywords: Belongingness needs; Relational Self; Collective Self; Inclusion needs; Scale construction; Well-being 
The Need for Inclusion: The Relationships between Relational and Collective Inclusion Needs and Psychological Well- and Ill-Being

A core motive of the self is the need to be accepted by others (Fiske, 2004; Sedikides, Hart, \& De Cremer, 2008). The Need for Inclusion reflects the psychological need to establish and/or maintain warm and friendly social relationships (see French \& Chadwich, 1956; Sokolowski, 2008). Because humans are social animals, the satisfaction of this need leads to psychological benefits in the form of well-being and happiness (Sheldon \& Bettencourt, 2002), and it helps "individuals to survive psychologically and physically" (Fiske, 2004, p. 18). The Need for Inclusion is considered to be a universal human motivation. Yet, there are cultural and individual differences in the way people express and satisfy this need, as well as differences in its psychological consequences (see Baumeister \& Leary, 1995).

Although the Need for Inclusion is an important human motive, it has not elicited much research attention. An allied concept, the Need to Belong, however, has yielded more scholarly efforts. Need to Belong has originally been defined by Baumeister and Leary (1995) as "a pervasive and fundamental human motivation that reflects the desire to form and maintain at least a minimum quantity of positive, continuous and significant interpersonal relationships with others" (p. 497). Schreindorfer and Leary (1996; Leary et. al., 2013) developed a self-reported measure of the Need To Belong. This Need to Belong Scale consists of items that measure either inclusion needs (sample item "I have a strong need to belong"), or the discomfort with social exclusion (sample item "I try hard not to do things that will make other people avoid or reject me"). With respect to the latter aspect, the authors hypothesized that if people are negatively affected by social exclusion, they should be considered to be high on Need to Belong. The Need to Belong Scale has been successfully used in empirical research as a one-dimensional measure (e.g. De Cremer \& Leonardelli, 2003; Loveland, Smeesters, \& Mandel, 2010; Mellor, Stokes, Firth, Hayashi, \& Cummins, 2008; Pickett, Gardner, \& Knowles, 2004; Van Hiel, De Cremer, \& Stouten, 2008).

The first aim of our research is to flesh out the distinction between inclusion needs and discomfort with social exclusion as separate concepts. The Need to Belong Scale predominantly focuses on the negative experience of exclusion, whereas the inclusion aspect is only poorly represented among its items. We argue that in order to study belongingness needs in their broadest meaning, it would be better to explicitly take into account the two aspects which constitute the concept. Specifically, we should jointly analyze the inclusion needs (poorly represented in the Need to Belong Scale) and the discomfort with exclusion 
(well-represented in the Need to Belong Scale). There is thus a definite need to develop a set of items that probes into inclusion needs specifically.

The second aim of this research is related to the fact that the items constituting the Need to Belong Scale are phrased in terms of "other people," without specifying who these others are, and without making a distinction between belongingness needs in terms of interpersonal relations on the one hand, and membership to social groups on the other hand. One can be motivated to form and maintain interpersonal relationships with significant others (i.e. relational belongingness needs), but a need to build meaningful relationships with social groups is possible as well (i.e. collective belongingness needs). The need to be included by close or significant others may well be different to the need to be included into social groups, but this possibility has not been explored yet. We therefore aimed to discern between these two levels, as such distinguishing between the relational and the collective self.

\section{The Need to Belong versus The Need for Inclusion: Conceptual and measurement issues}

In terms of their definitions, the Need to Belong and the Need for Inclusion show high resemblance. In this context, the distinction between inclusion needs and discomfort with exclusion is important, and this issue becomes particularly clear when looking at the level of measurement of the Need to Belong Scale. Indeed, a closer look at the 10-item Need to Belong Scale (Leary et. al., 2013; Schreindorfer \& Leary, 1996) reveals that it is more strongly focused on negative affect, with many items worded in terms of "does not bother me" (items 1 and 7), "seldom worry" (item 3), "do not like" (item 6), "it bothers me" (item 9), and "feelings are hurt" (item 10). The positive side of belongingness and inclusion is clearly represented by (only) two items: "I want other people to accept me" (item 5) and "I have a strong need to belong" (item 8). Finally, one item can be seen as a positive orientation, but its context is negative: "I have to feel that there are people that I can turn to in times of need" (item 4). In our opinion, the Need to Belong Scale is dominated by items tapping into negative reactions and indifference, at the cost of the positive side of inclusion. Admittedly, feelings of being excluded can cause negative reactions like distress, sadness, pain, or anger (Williams, Forgas, \& von Hippel, 2005), but it should also be acknowledged that the experience of inclusion is positively related with positive emotions like self-esteem and wellbeing (Baumeister, 1991; Tyler \& Lind, 1992; Valkenburg, Peter, \& Schouten, 2006). Those suffering most from rejection by others might show higher levels of ill-being and lower levels of well-being, whereas those positively inclined to others might show an opposite pattern.

Hence, in order to understand belongingness needs, there is a definite need for more attention to the inclusion facet. Indeed, the relative underrepresentation of items measuring 
inclusion needs in the Need to Belong Scale (Leary et. al., 2013; Schreindorfer \& Leary, 1996) may obscure the theoretical preconceived positive relationships of belongingness with well-being and self-esteem.

\section{Inclusion and exclusion: Related constructs and relationship with well-being}

The Need for Inclusion is closely related to other motivational constructs. In this context, two separate (though related) motives can be distinguished. On the one hand, French and Chadwich (1956) refer to the affiliation motive as a desire "to establish and/or maintain warm and friendly interpersonal relationships" (p. 296). This motive is primarily concerned with building and maintaining more 'distant' relationships with people and acquaintances. On the other hand, the intimacy motive focuses primarily on close relationships with significant others (Sokolowski, 2008). Schönbrodt and Gerstenberg (2012) constructed a Unified Motive Scale (UMS) in which the domains of affiliation motive and intimacy motives were included. Along similar lines, the importance of relational needs in terms of close others has also been stressed by Self-Determination Theory (Deci \& Ryan, 2000). According to this perspective, relational needs are intrinsic, that is, rewarding in itself. The relatedness need as conceptualized in Self-Determination Theory is conceptually close to the Need for Inclusion (see Sheldon \& Gunz, 2009).

As inclusion needs are about connections with other people, we hypothesized that Need for Inclusion is a positive orientation that contributes to well-being. Conversely, discomfort with exclusion - well-represented in the Need to Belong scale - can be expected to relate to ill-being. At least two theoretical frameworks support such a pattern of relationships. First, inclusion needs and discomfort with exclusion can be considered to constitute specific representations of the more general Approach and Avoidance motivations, respectively. Approach motivation is the inclination to move towards desired end-states, whereas Avoidance motivation represents the tendency to avoid undesired, aversive end-states (e.g. Gable, 2006; Gray, 1987). The Need for Inclusion, then, can be understood as a specific approach motivation towards social relationships, whereas the discomfort with exclusion can be considered as a specific form of motivation aimed to avoid the rejection of others. Importantly, Approach and Avoidance motivations differently contribute to well-being and relational variables, with Approach motivation being positively related to psychological wellbeing and social integration, and Avoidance motivation being positively related to ill-being, loneliness and relationship insecurity (Gable, 2006).

Secondly, according to Self-Determination Theory (Deci \& Ryan, 2000; Vansteenkiste, Lens, Soenens \&, Luyckx, 2006), the need to form bonds and meaningful 
relationships with other individuals contributes to greater well-being. Building on SelfDetermination Theory, Lavigne, Vallerand, and Crevier-Braud (2011) made a distinction between a Growth Orientation and a Deficit Reduction Orientation underlying belongingness needs. The Growth Orientation directs itself to interpersonal actualization, a genuine interest in social relationships and the wish to commit oneself to significant others, by being open without being afraid of negative judgements. The Deficit Reduction Orientation is the desire to be close to others in order to fill a social void, or in the words of Lavigne et al. (2011): "a constant craving for social acceptance" (p. 1186). These authors constructed scales to measure these two underlying orientations of belongingness needs, and they revealed that the Growth Orientation contributes to psychological well-being, whereas the Deficit Reduction Orientation contributes, among others, to social anxiety and lowered self-esteem. As this research shows, and in line with our expectations, a (albeit specific) positive orientation towards social bonds contributes to well-being, whereas other orientations do not have this potential, and even may contribute negatively. Our approach differs from Lavigne et al.'s (2011) work, because we consider inclusion as a positive and desired outcome, irrespective of whether growth or deficit reduction is the underlying goal. For instance, if a person wants to be in the company of others for selfish reasons, than we would consider this to be a manifestation of the positive side of inclusion.

Therefore, the first contribution of the present research is to further flesh out the distinction between inclusion and exclusion. We particularly focus on a positive orientation towards the creation of social bonds, and aim to show its utility to explain well-being above and beyond the currently used Need to Belong Scale (Leary et. al., 2013; Schreindorfer \& Leary, 1996).

\section{Different levels of Self}

Besides fleshing out the distinction between inclusion and exclusion, a second important aim of the present paper was to discern between different levels of self. The self indeed consists of various levels (Brewer \& Gardner, 1996; Johnson, Selenta, \& Lord, 2006; Lord, Brown, \& Freiberg, 1999; Sedikides, 2001). In the context of the Need for Inclusion, the relational and collective selves are of particular interest. Some authors have located the Need to Belong at the level of interpersonal relationships, whereas others point to the potential importance of belongingness needs at the level of social groups. For instance, Baumeister and Leary (1995) defined the Need to Belong as a pervasive and fundamental human motivation that reflects the desire to form and maintain at least a minimum quantity of 
positive, continuous and significant interpersonal relationships with others (p. 497) .

However, Leary and his colleagues (2013) stated that the Need to Belong refers to the need to be accepted by others as well as the need to belong to social groups. Likewise, scholars have identified the Need to Belong as a basis of the human tendency to form groups (Forsyth, 1990), and it has also been argued that it helps people within the group to coordinate their actions and operate effectively (Levine \& Kerr, 2007). However, at the level of its measurement no distinction has been made between the relational and collective levels.

Building on this distinction between different levels of the self, Relational Need for Inclusion then refers to the desire of an individual to find interpersonal acceptance and belongingness with significant others (like partners, family members, or friends), whereas Collective Need for Inclusion refers to the motivation to be accepted by specific social groups. The Need for Inclusion may indeed motivate people to affiliate themselves with interpersonal networks as well as with social groups (Vignoles, Regalia, Manzi, Golledge, \& Scabini, 2006). Therefore, an important aim of the present study is to construct items both for Relational and for Collective Need for Inclusion.

\section{Collective Need for Inclusion: Proximal Outcomes.}

Given that no previous study has focused on the Collective Need for Inclusion, it is important to discern this concept from other related concepts. According to SelfCategorization Theory (Turner, Hogg, Oakes, Reicher, \& Wetherell, 1987), part of our identity is based on the information we receive from the groups to which we belong (Hornsey \& Jetten, 2004), and groups are also an important source of self-esteem (Luhtanen \& Crocker, 1992). However, the Collective Need for Inclusion should be discerned from the notion of group identification for at least two reasons. First, the Collective Need for Inclusion involves an individual's orientation towards social groups in general, which thus applies to multiple groups at the same time. In contrast, group identification typically targets one particular group at a time (e.g. Leach et al., 2008; Phinney, 1992). People high in Collective Need for Inclusion can thus be expected to identify more with social groups in general, but this tendency may reveal itself for some groups, but not for other groups. Second, and even more important, group identification essentially captures existing feelings of being connected to other group members and seeing one's self as a part of the group. Collective Need for Inclusion, however, involves the need to have these experiences of feeling connected to the group, and is not about the feelings themselves.

Another construct that should be discerned from the Need for Inclusion is collective self-esteem (Luthanen \& Crocker, 1992). Collective self-esteem encompasses aspects 
contingent on group inclusion, such as group identification, membership experiences, and evaluation of the group. The notion of Collective Need for Inclusion can be considered as an antecedent of group membership, whereas collective self-esteem can be regarded as a consequence of group membership. Indeed, given that people seek satisfaction of their needs (e.g. Sheldon \& Gunz, 2009), high levels of the Collective Need for Inclusion motivate people to affiliate with social groups, which in turn, can be expected to relate positively to group identification and collective self-esteem.

\section{Collective Need for Inclusion: Distal Outcomes.}

The Need for Inclusion has even more to offer to the study of collective and group processes. Also on a more societal level, Collective Need for Inclusion may contribute to social trust. Putnam (2000) argued that social trust fosters a strong civil society, facilitates collective behavior and encourages citizenship behavior and political action. Trust is best achieved when one feels connected with other persons, like for instance by being a member of the same ingroup (e.g. Kramer, 1993; Kramer, Hanna, Su, \& Wei, 2001), or by being connected through a superordinate group (Dovidio, Gaertner, Niemann, \& Snider, 2001).

\section{The present research}

The aim of the present research was to investigate the role of the Need for Inclusion, both in terms of the relational self and the collective self. In Study 1, we developed a set of Relational and Collective Need for Inclusion items and we tested if the relational and collective scales form distinctive factors and constitute internally consistent scales. Study 2 aimed to investigate the discriminant and incremental validity of the Relational and Collective Need for Inclusion and the Need to Belong Scale (Leary et al., 2013; Schreindorfer \& Leary, 1996) for well- and ill-being and for collective variables such as social trust, social acceptance, collective self-esteem, and group identification. Moreover, we also investigated the relationships between the Need for Inclusion Measures and actually experienced belongingness.

\section{Study 1}

The aim of Study 1 was to develop and test items of Relational and Collective Need for Inclusion Measures and to subsequently submit these items to factor-analysis.

\section{Method}

\section{Participants.}

Based on recommendations in literature for initial scale validation (Boateng, Neilands, Frongillo, Melgar-Quiñonez, \& Young, 2018; Clarke \& Watson, 1995; Comrey \& Lee, 
2013), we recruited a sample of 200 American adults through Prolific Academic. The duration of the study was 6-7 minutes and the respondents were paid 0.70 American dollar (approximately 0.64 euro) for their participation. In this sample, 13 out of 200 respondents were excluded from the analyses because they incorrectly answered at least one of the two included check-questions (for example: 'Please select the second response box for this question'). The final sample thus consisted of 187 respondents, including $54.5 \%$ women and $45.5 \%$ men (age: $M=36.68, S D=11.99$ ). More descriptive statistics of the sample can be found in Table 1. Given that the final focus of our analyses lay in unraveling the dimensional structure of our newly formed measure -and hence, distinguishing items referring to Relational and Collective Need for Inclusion- we conducted a sensitivity analysis with the semTools package (Jorgensen, Pornprasertmanit, Schoemann, \& Rosseel, 2018) in R (R Core Team, 2013). Sensitivity analysis allows for assessing the minimum detectable effect when sample sizes are predetermined (Cohen, 1988). In our case, this boiled down to testing which difference in the Root Mean Square Error of Approximation [RMSEA] between a one- and two-factor model of Relational and Collective Need for Inclusion could be obtained under standard criteria (significance level $\alpha=.05$ and $80 \%$ power).Results of this analysis revealed that the minimum detectable population effect size for our Study was $\Delta_{\mathrm{RMSEA}}=.036$, which was below the obtained difference in RMSEA, thereby corroborating the validity of our structural analyses.

Insert Table 1 about here

\section{Measures.}

\section{Relational and Collective Inclusion Needs.}

We started from a set of items that was generated by five doctoral students and a postdoctoral researcher in social psychology ${ }^{1}$. We gave them a sheet of paper with the definition of belongingness (Baumeister \& Leary; 1995), which explicitly focuses on inclusion: "The belongingness hypothesis states that people have a pervasive drive to form and maintain lasting and positive relationships with others". For the Relational Need for Inclusion we added the sentence "We are interested in need to belong at the level of interpersonal relationships, that is, the need to be with significant others" and gave the following example: 'I want my significant others to accept me'. For Collective Need for Inclusion, the following 
sentence was given: "We are interested in need to belong at the level of the collective and the group, that is, the need to belong to social groups", as well as an example of a sample item: 'I love to be part of a group'. The panel members were then invited to generate three or four possible items. After collecting their responses, which were completed individually, duplicate or very similar items were deleted from the list. Next, we consulted an expert on SelfDetermination Theory in our department and adjusted the items so that these truly reflected the need itself. References to need satisfaction and need frustration were avoided, as well as any other reference to psychological benefits or costs associated with the need. This resulted in the construction of 21 items for Collective Need for Inclusion and 22 items for Relational Need for Inclusion.

All items were then administered to our online sample and respondents had to indicate on five-point Likert scales the degree to which they felt each statement was true or characteristic of them $(1=$ strongly disagree, $2=$ disagree, $3=$ neither agree nor disagree, $4=$ agree, 5 = strongly agree). For Relational Need for Inclusion, we referred in the introductory sentence of the questionnaire to "relationships with significant others, like family members, friends or people you know well". For the items of Collective Need for Inclusion, the introductory sentence described a group: "groups can be diverse, like when someone is a supporter of a sports team or a member of an organization or association. Conversely, you can also belong to groups you do not choose yourself, such as when you are a member of a minority group, or your nationality. What is typical is that groups can be more important for one individual than for other individuals".

\section{Results}

\section{Initial analyses.}

Because the items are new and hence have never been submitted to structural analyses before, we used exploratory analyses to check the underlying structure. Principal Component Analysis (PCA), with two fixed factors and OBLIMIN rotation (eigenvalues 16.27 and 6.96 before rotation and 13.12 and 13.13 after rotation) was performed on the Relational and Collective Need for Inclusion items. The aim of this PCA was to check whether the relational and collective items would load on distinctive factors. The items indeed showed high loadings on their respective components, which could be straightforwardly interpreted to reflect relational (primary loadings between .48 and.83) and collective (primary loadings between .44 and.89) inclusion needs. The items and their loadings can be found in the online Appendix 1. The components were significantly related $(r=.32, \mathrm{p}<.001)$. 
In the next phase, we selected a more parsimonious set of 10 items for the Relational Need for Inclusion scale and 10 items for the Collective Need for Inclusion scale. We decided on 10 items because the Need to Belong Scale (Leary et. al., 2013; Schreindorfer \& Leary, 1996) is also composed of this particular number of items. As a first criterion for an item, we selected those items that had the highest loadings (often higher than .70). Next, we searched for groups of items that express a similar idea, and selected one of them. This procedure ensured us that the items would show enough dissimilarity in order to have a set of items that varies in specific content. The reason why particular items were included or excluded can be found in the online Appendix 1.

Reliability analysis showed high internal consistency for both $2 \times 10$ item sets $(\alpha=.92$, $M=4.02, S D=0.69$ and $\alpha=.93, M=2.66, S D=0.88$, for Relational Need for Inclusion and Collective Need for Inclusion respectively). The correlation between the reduced ten-item set and the full-item set was highly significant for Relational Need for Inclusion $(r=.97, p<$ $.001)$ and Collective Need for Inclusion $(r=.99, p<.001)$. The correlations between the reduced set and the principal components based on the complete item set were also highly significant ( $r$ 's $=.98$ and .99 , respectively, $p$ 's $<.001$ ).

\section{Validation.}

We used Exploratory Structural Equation Modeling (ESEM; Asparouhov \& Muthén, 2009) through Mplus 7.4 (Muthén \& Muthén, 1998-2015) because this technique integrates the advantages of both a standard confirmatory factor analysis (i.e., assessing the fit of an a priori model using different SEM parameters and specification of correlated residuals) and exploratory factor analysis (i.e., estimations of cross loadings; Marsh, Morin, Parker, \& Kaur, 2014; Wiesner \& Schanding, 2013). In order to estimate model parameters, we used Robust Maximum Likelihood Estimation on all data.

Following recommendations by $\mathrm{Hu}$ and Bentler (1998) and MacCallum and Austin (2000), we examined the Root Mean Squared Error of Approximation (RMSEA, Steiger \& Lind, 1980), the Standardized Root Mean Squared Residual (SRMR, Bentler, 1995), and Comparative Fit Index (CFI, Bentler, 1990) to evaluate the goodness of fit of the measurement model. Values of a $\chi^{2} / \mathrm{df} \leq 2$ point to a very good model fit, values $\leq 3$ suggest a good model fit and values $\leq 5$ indicate an acceptable model fit (Kline, 2015; Schumacker \& Lomax, 2004). According to Hu and Bentler (1999), cut-off values $\geq .95$ for the CFI indicate a good model fit. For RMSEA, values $\leq .08$ suggest an acceptable model fit, and values $\leq .05$ indicate a good model fit (Chen, Curran, Bollen, Kirby, \& Paxton, 2008). Cut-off values $\leq$ .08 for the SRMR suggest a good model fit (Hu \& Bentler, 1999). Although frequently used, 
these cut-off values should be handled with caution as factor loadings are usually lower in social sciences (Heene, Hilbert, Draxler, Ziegler, \& Bühner, 2011).

ESEM showed adequate fit for the 2x10-item measurement model of Relational and Collective Need for Inclusion, $\chi^{2}(\mathrm{df}=169)=289.45, p<.001\left(\chi^{2} / \mathrm{df}=1.92\right), \mathrm{CFI}=0.94$, RMSEA $=.07$ and SRMR $=0.04$. This two-dimensional model showed a significantly better fit than the one-dimensional model, $\chi^{2}(\mathrm{df}=170)=1139.71, p<.001\left(\chi^{2} / \mathrm{df}=6.70\right), \mathrm{CFI}=$ $0.55, \mathrm{RMSEA}=.18$ and $\mathrm{SRMR}=.18$. The factor loadings of the items on the two dimensions are shown in Table 2. The correlation between the two Need for Inclusion dimensions was found to be positive $(r=.40, p<.001)$.

Insert Table 2 about here

\section{Discussion}

The present results show that we successfully constructed internally consistent measures of Relational and Collective Need for Inclusion. Factor analyses revealed that the items constituting Relational and Collective Need for Inclusion loaded on distinct but related dimensions. The fit indices of the two-factorial model were satisfactory.

\section{Study 2}

Study 2 had two major aims. First, we wanted to test the distinctiveness of the Need for Inclusion and several other, closely allied constructs. In order to achieve this aim, we conducted several factor analyses which checked for item overlap between the Need for Inclusion and these other constructs. Second, we wanted to test the pattern of relationships of Need for Inclusion and Need to Belong with several target variables related to well- and illbeing on the collective level (e.g., group identification and social trust). In order to achieve the latter aim, we conducted regression and mediation analyses.

\section{Empirical distinctiveness of the Need for Inclusion.}

We wanted to investigate the distinctiveness of the Need for Inclusion an several other scales. Firstly, we checked for item overlap of the Need for Inclusion scales and two measures of experienced levels of actual belongingness. The two scales selected for comparison were the General Belongingness Scale (GBS, Malone, Pillow, \& Osman, 2012) and the Sense of Belonging Instrument (SOBI, Hagerty \& Patusky, 1995). Both the GBS and the SOBI measure a general sense of belongingness, yet they show differences as well. The items of SOBI primarily aim to capture a sense of belonging by assessing the lack of 
exclusion experiences. The GBS taps into one's general sense of belonging, measuring both a sense of achieved belonging as well as a lack of exclusion (Malone et. al., 2012).

In order to establish the distinctiveness of the Need for Inclusion, we also included a measure of relatedness need satisfaction and frustration as well as relatedness need valuation. In developing our need items in Study 1, we tried to not include any reference to need satisfaction and frustration, which refer not to the need itself, but rather to one's ability to fulfill the need. In Study 2, we wanted to test empirically the distinctiveness of these concepts (in order to check whether our attempt to exclude such content was successful).

\section{Relationship with psychological and collective target variables.}

Because belongingness can help to maintain and protect mental and psychological health (Bolger, Zukerman, \& Kessler, 2000; Spiegel, Bloom, Kraemer, \& Gottheil, 1989), and benefits the individual by increasing psychological well-being (Baumeister, 1991; Deci \& Ryan, 2000; Tyler \& Lind, 1992; Valkenburg et al., 2006; Vansteenkiste et. al., 2006), Study 2 aimed to investigate the relationships of the Relational and Collective Need for Inclusion scales with a number of relevant psychological and collective target variables, i.e., general mental health, subjective happiness, subjective well-being, personal self-esteem, positive affect, negative affect, and avoidance/anxiety of close relationships, social trust, social acceptance, collective self-esteem, group-identification, relatedness needs, relatedness satisfaction and relatedness frustration. We also investigated the differential relationships of the Relational and Collective Need for Inclusion scales and the Need to Belong Scale with these target variables. We expected that Relational and Collective Need for Inclusion positively contribute to positive outcomes (i.e., subjective happiness, subjective well-being, personal self-esteem, positive affect, social trust, social acceptance, collective self-esteem and relatedness satisfaction), and negatively contribute to the negative outcomes (i.e., poor mental health, negative affect, avoidance of close relationships, anxiety of close relationships and relatedness frustration). However, we expected a reverse pattern of correlations for Leary's Need to Belong Scale.

We also included some variables that are closely related to or expected to be driven by the Collective Need for Inclusion. Specifically, we complemented our array of 'individual' positive mental state variables by including the more 'collective' variables of social trust and social acceptance. Moreover, as we have mentioned above, collective self-esteem and groupidentification can be considered closely related outcomes.

\section{Two-wave design.}


We used a two-wave design of data gathering. In the first wave, we administered the 2x10-item Need for Inclusion scales, the Need to Belong Scale by Leary and colleagues (2013; Schreindorfer \& Leary, 1996), the two Sense of Belongingness measures (SOBI and GBS), Relatedness Valuation, Relatedness Needs Frustration and Satisfaction, Collective Self-Esteem and Group Identification, in order to establish discriminant validity. For the second wave, we invited the same participants three weeks later to fill in a questionnaire with the scales to measure the remaining psychological and collective target variables, so we could examine the relationships of the constructs obtained in phase 1 with psychological and societal well-being.

\section{Method}

\section{Participants.}

We recruited a sample of American citizens through Prolific Academic in two waves. Given that our current interests laid in confirming the dimensional structure of the Need for Inclusion scales as well as in establishing its discriminant validity with respect to related psychological constructs, we adopted a conservative approach and opted for a slightly bigger sample than in Study 1. It has been suggested that, for confirmatory factor analyses, sample sizes between 200 and 300 subjects are a reasonable choice (Williams, Onsman, \& Brown, 2010; Yong \& Pearce, 2013). As such, we recruited 286 participants in our first wave of data collection. A large part of this sample also participated in the second part of the study (87\%, $N=250$ ). We only included those participants in analyses that participated in both parts of the study. After controlling for the incorrect check-questions, the final sample included 242 respondents who participated in both waves (64\% females and $36 \%$ males; age: $M=35.33$, $S D=12.16)$. They were paid $1.3 £(1.43$ euro) and $1 £(1.11$ euro) for their participation in wave 1 and 2, respectively. For more descriptive information on the sample, please see Table 3. Results of a sensitivity analysis revealed that, with the aforementioned sample size and under standard criteria (significance level $\alpha=.05$ ), our study had approximately $98 \%$ power to detect the present difference of .012 between the RMSEAs of the null- and the alternative model in our nine ESEM analyses (see below).

\section{Insert Table 3 about here}

\section{Measures.}

Measures wave 1 and wave 2. 
Unless indicated otherwise, all items were administered using five-point Likert scales $(1=$ strongly disagree, $2=$ disagree, $3=$ neither agree nor disagree, $4=$ agree, $5=$ strongly agree).

Relational and Collective Need for Inclusion Scale. We administered the item set developed in Study 1 at T1 and T2. Internal consistency of the 10-item scales was high, both at $\mathrm{T} 1(\alpha=.90, M=4.08, S D=.63$ and $\alpha=.92, M=2.78, S D=.86)$, for the Relational and Collective scales, respectively) and at T2 $(\alpha=.91, M=4.03, S D=.63$ and $\alpha=.93, M=2.81$, $S D=.79$, respectively). T1 was used in further analyses.

\section{Measures Wave 1.}

Need To Belong Scale. We administered the scale for Need to Belong from Leary and his colleagues (Leary et. al., 2013; Schreindorfer \& Leary, 1996). Internal consistency was high $(\alpha=.85, M=3.18, S D=.72)$.

Sense of Belonging Instrument-Psychological Experiences (SOBI-P). This 18-item self-report measure was developed to measure the psychological experience of a sense of belonging in adults (Hagerty \& Patusky, 1995). Examples of items are: 'I feel like a piece of a jigsaw puzzle that doesn't fit into the puzzle' and 'If I died tomorrow, very few people would come to my funeral'. Seventeen items were reversed, because a higher score indicates a higher sense of belonging ( $\alpha=.96, M=3.41, S D=1.01$ ).

Sense of Belonging Instrument-Antecedents (SOBI-A). This nine-item self-report measure by Hagerty and Patusky (1995) measures the antecedents or precursors of sense of belonging. Some examples of items are: 'In the past, I have felt valued and important to others' or 'Generally, other people recognize my strengths and good points' ( $\alpha=.74, M=$ $3.60, S D=.52)$.

General belongingness Scale (GBS). We used this 12-item instrument to measure a general sense of belonging (Malone et al., 2012). An example item is 'I feel isolated from the rest of the world' (reversed coded). Internal consistency was high $(\alpha=.95, M=3.57, S D=$ $.90)$.

Relatedness valuation. Six items were used to measure relatedness needs (Van den Broeck, Vansteenkiste, De Witte, Soenens, \& Lens, 2010). A sample items is: 'In life, I feel part of social groups'. Internal consistency was high ( $\alpha=.88, M=3.36, S D=.93)$.

Relatedness Needs Frustration and Satisfaction. We administered the two 4-item measures of Chen and colleagues (2015) probing into relatedness frustration and satisfaction. Sample items are 'I feel close and connected with other people who are important to me' and 'I feel excluded from the group that I want to belong to', respectively. Internal consistency

This article is protected by copyright. All rights reserved 
was high $(\alpha=.84, M=2.10, S D=.96$ and $\alpha=.90, M=3.89, S D=.85$, for frustration and satisfaction, respectively).

Collective self-esteem. The 16-item scale of Luhtanen and Crocker (1992) was used to measure collective self-esteem. This scale consists of four subscales of collective self-esteem, each containing four items. An example of the 'membership' subscale is 'I am a worthy member of the social groups I belong to' $(\alpha=.85, M=3.50, S D=.90)$. An item example of the 'private' subscale is 'In general, I'm glad to be a member of the social groups I belong to' $(\alpha=.84, M=3.74, S D=.79)$, an item example of the 'public' subscale is 'Most people consider my social groups to be more ineffective than other groups' $(\alpha=.81, M=3.61, S D=$ .74) and lastly, an item of the 'identity' subscale is 'In general, belonging to social groups is an import part of my self-image' $(\alpha=.71, M=2.89, S D=.77)$. Internal consistency of this total scale was high $(\alpha=.89, M=3.52, S D=.65)$.

Group identification. The 5-component scale by Leach and colleagues (2008) was administered to measure identification with the various groups one belongs to. The scale consists of five different identification facet scales. Example items for each component are: 'I feel a bond with the social groups I belong to' (solidarity, three items, $\alpha=.90, M=3.44, S D$ $=.95$ ), 'I think that the social groups I belong to have a lot to be proud of' (satisfaction, four items, $\alpha=.92, M=3.67, S D=.82$ ), 'The fact that I am a member of the social groups I belong to is an important part of my identity' (centrality, three items, $\alpha=.88, M=2.89, S D=$ .94), 'I have a lot in common with the average person in the social groups I belong to' (individual self-stereotyping, two items, $\alpha=.91, M=3.25, S D=.96$ ) and 'People in the social groups I belong to are very similar to each other' (in-group homogeneity, two items, $\alpha$ $=.80, M=3.41, S D=.84)$. The total scale yielded a high internal consistency $(\alpha=.94, M=$ $3.36, S D=.75)$.

\section{Measures Wave 2.}

Subjective Happiness. This 4-item scale measures global subjective happiness and asks whether the respondent thinks he or she is more or less happy compared to others, e.g., "Compared to most of my peers, I consider myself: (1) less happy vs. (5) more happy" $(\alpha=$ .89, $M=3.10, S D=.96$ ) (Lyubomirsky \& Lepper, 1999).

The Satisfaction with Life Scale (SLS). This five-item scale measures one's subjective well-being (Diener, Emmons, Larsen \& Griffin, 1985; $\alpha=.87, M=2.89, S D=.91$ ).

Respondents had to indicate whether they agree or disagree with certain statements such as 'My life is close to my ideal'. 
Self-Esteem. For the measurement of individual self-esteem, we used a single-item measure (Robins, Hendin \& Trzesniewski, 2001). Respondents had to answer the item 'I have a high self-esteem' on a Likert scale ranging from $1=$ Not very true of me to $5=$ very true of me $(M=2.57, S D=1.12)$.

Positive and Negative Affect. To measure positive and negative affect, we used a shortened version of the PANAS (Roets \& Van Hiel, 2008; Watson, Clark, \& Tellegen, 1988). This version consisted of two six-items scales that assess the tendency to experience Positive Affect (PA, e.g., excited and relaxed) and Negative Affect (NA, e.g., hostile and depressed) ( $1=$ very weak, $5=$ very strong). These two scales showed sufficient internal consistency $(\alpha=.82, M=2.94, S D=.73$ for PA, and $\alpha=.82, M=2.60, S D=0.81$ for NA).

General Health Questionnaire $(G H Q)$. This 12-item measure assesses mental health (Banks, et al., 1980), including items such as 'Have you recently lost much sleep over worry?' and 'Have you recently been losing confidence in yourself?', which are answered on a Likert scale, ranging from $1=$ Not at all, to $5=$ Much more than usual $(\alpha=.92, M=2.79$, $S D=0.83)$.

Experiences in Close Relationships (ECR). This 10-item instrument (Fraley, Heffernan, Vicary, \& Brumbaugh, 2011) assesses adult attachment and consists of two subscales, one concerning 'avoidance' of close relationships (6 items; e.g., "I don't feel comfortable opening up to other persons"; $\alpha=.84, M=2.93, S D=.81$ ), and one measuring 'anxiety' for close relationships (4 items; e.g., "I don't fully trust other persons"; $\alpha=.85, M=$ 3.03, $S D=1.04)$.

Social trust. To measure social trust, we administered the Social Trust Scale (see Burns \& Kinder, 2000) which consists of six items (e.g., 'Generally speaking, I would say that most people can be trusted') and its internal consistency was good ( $\alpha=.85, M=3.01, S D$ $=0.67)$.

Social acceptance. We administered the 7 items of the social acceptance facet scale of Keyes' (1998) social well-being measure. A sample item of social acceptance is: "People do not care about other people's problems" ( $\alpha=.89, M=2.96, S D=0.72)$.

\section{Results}

\section{Psychometric analyses.}

Factor-analyses (ESEM) showed an adequate fit of the 2x10-item measurement model of Relational and Collective Need for Inclusion at T1, $\chi^{2}(\mathrm{df}=151)=264.03, p<.001\left(\chi^{2} / \mathrm{df}=\right.$ $1.75), \mathrm{CFI}=0.95, \mathrm{RMSEA}=.06$, and SRMR $=0.03$. This two-dimensional model showed a 
significantly better fit than the one-dimensional model, $\chi^{2}(\mathrm{df}=170)=1250.31, p<.001\left(\chi^{2} / \mathrm{df}\right.$ $=7.35), \mathrm{CFI}=0.60, \mathrm{RMSEA}=.16$ and $\mathrm{SRMR}=.17$. The correlation between the two dimensions was significant, $r=.39$.

The relationship between the first and second measurement of Relational and Collective Need for Inclusion across the three-week interval between was adequate $(r=.78$ and .75 , respectively) in terms of test-retest reliability.

The items of the Relational Need for Inclusion elicited significantly more agreement among our respondents than the Need to Belong ( $M$ 's: 4.08 versus $3.18 ; t(\mathrm{df}=241)=23.90$, $\mathrm{p}<.001)$, which in turn yielded higher scores than the Collective Need for Inclusion ( $M$ 's: 3.18 versus $2.78 ; t(\mathrm{df}=241)=7.93, \mathrm{p}<.001)$.

\section{Empirical distinctiveness of the Need for Inclusion.}

In order to establish discriminant validity, we performed nine ESEM analyses. For each of these analyses the items of the Relational and Collective Need for Inclusion scales were included together with the items of one of the following scales: (1) Need to Belong, (2) SOBI-P, (3) SOBI-A, (4) GBS, (5) Collective Self-Esteem, (6) Group Identification, (7) Relatedness Valuation, (8) Relatedness Satisfaction, and (9) Relatedness Frustration. In seven of these analyses, all items of the respective scales had their primary loadings on a distinct factor, as such evincing of distinctiveness. Specifically, all Relational and Collective items loaded on 'their' factors, and all items of the third variable also loaded on their 'own' factor. Two analyses, however, revealed some problematic items. First, joint analysis with the Need to Belong Scale revealed that three items of Need to Belong loaded among the Relational Need for Inclusion items ("I do not like to be alone", "Being apart from my friends for long periods of time does not bother me" and "I have a strong need to belong"). One Need to Belong item had a primary loading on the Collective Need for Inclusion factor (i.e., "I need to feel that there are people I can turn to in times of need") ${ }^{2}$. Second, the analysis for Collective Self-Esteem revealed that two Self-Esteem items ("In general, belonging to social groups is an important part of my self-image" and "The social groups I belong to are unimportant to my sense of what kind of a person I am") had their primary loading on the Collective Need for Inclusion factor. Because of this predictor-criterion overlap, we omitted these items from the Collective Self-Esteem scale when running the subsequent analyses $(\alpha=$ $0.89, M=3.52, S D=.65)$. The analyses are reported in detail in the online Appendix 2.

\section{Correlational analyses.}


We computed correlations of the Need for Inclusion and the Need to Belong (Leary et. al., 2013; Schreindorfer \& Leary, 1996) scales with the sense of belongingness scales. These analyses showed that Relational Need for Inclusion was significantly related to sense of belongingness ( $r$ 's $=.19$ and $.28, p$ 's $<.001$, for SOBI-P and GBS, respectively), whereas Collective Need for Inclusion was significantly related to GBS $(r=.15, p<.05)$ and yielded a positive relationship with SOBI-P, which however failed to reach the conventional significance levels $(r=.11, p<.10)$. The Need to Belong Scale by Leary and his colleagues showed a negative relationship with sense of belongingness ( $r$ 's $=-.20$ and $-.16, p$ 's $<.01$, for SOBI-P and GBS, respectively).

The correlations of the two Need for Inclusion scales and the Need to Belong Scale with the well-being and ill-being variables are reported in Table 4.

Insert Table 4 about here

\section{Regression analyses.}

Next, we conducted regression analyses (see Table 5) for each of the outcome variables. These analyses thus show the unique contributions of each predictor variable. We added all three 'need' scales together as independent variables in the regression model. Multicollinearity proved to be at acceptable levels (the Variation Inflation Factors, VIFs $<1.85$, which is far below the recommended threshold value of 10). The results showed unique positive relationships between Relational and Collective Need for Inclusion (measured at T1) and the positive outcomes, and a negative relationship with the variables that refer to negative reactions. An opposite pattern of results emerged for the Need to Belong Scale. Another noteworthy result is that the Need for Inclusion scales showed positive regression coefficients for Relatedness Valuation and Needs Satisfaction, and negative relationships with needs frustration. Again, this pattern of results was opposite for Need to Belong.

Insert Table 5 about here

\section{Direct and indirect effects.}

Comparison of the magnitude of the correlations (see Table 4) with the magnitude of the regression coefficients (Table 5) reveals rather large discrepancies. Specifically, the raw correlations were generally weaker than the regression coefficients, which is indicative of suppression effects. These effects can be due to the Need for Inclusion and Need to Belong 
scales showing strong positive relationships with each other, but at the same time showing relationships of opposite sign with the outcome variables. In other words, the variance that is shared between Need for Inclusion and Need to Belong tends to oppose the effects of the unique part of one of these variables. This can be clarified best by comparing the direct effect of a scale with the indirect effects through the others scales. Table 6 reports the effects of these exploratory analyses. As can be seen in this Table, almost all total effects are composed by counteracting direct and indirect effects that tend to cancel out each other. Specifically, for the well-being variables, the direct effect of the Need for Inclusion scales is positive, whereas the indirect effect through the Need to Belong Scale is negative. The Need to Belong Scale has negative direct effects on well-being, but its indirect effects trough the Need for Inclusion scales have a positive sign. For the ill-being variables, this pattern of relationship reverses, with negative direct effects for the Need for Inclusion scales and positive indirect effects via the Need to Belong Scale, and positive direct effects for the Need to Belong Scale and negative indirect effects trough the Need for Inclusion scales.

Insert Table 6 about here

\section{Discussion}

Study 2 revealed that although Relational and Collective Need for Inclusion, and sense of belonging are related constructs, they still are empirically distinctive. As can be reasonably expected, higher Need for Inclusion tends to go together with higher sense of belonging, which illustrates that inclusion needs tend to be gratified as people generally try to fulfill their needs. The regression analyses revealed positive, unique relationships between Relational and Collective Need for Inclusion and psychological well-being emerged, whereas a pattern of negative relationships was obtained for ill-being. An opposite pattern of results emerged for the Need to Belong Scale (Leary et. al., 2013; Schreindorfer \& Leary, 1996), with significant negative relationships with positive states and positive relationships with negative mental states. These analyses thus reveal that both Relational and Collective Need for Inclusion independently contribute to more well-being and to less ill-being. Also, both Need for Inclusion scales independently and positively contributed to Relational Needs and

Relational Needs Satisfaction, as well as to collective outcomes such as Collective SelfEsteem and Group Identification. The opposite pattern was revealed for Need to Belong.

\section{General discussion}


In the present contribution, we aimed to investigate the distinct effects of inclusion needs on psychological well-being and ill-being. We aimed to show that people who appreciate the company of others and who ascribe high importance to others liking them, are in fact in a better psychological shape than those who are relatively less oriented towards others. Need for inclusion is a part of the more general Need to Belong, which comprises discomfort with exclusion as well, and which is measured most commonly by the Need to Belong scale (Leary et. al., 2013; Schreindorfer \& Leary, 1996). However, the Need to Belong Scale is somewhat skewed to (the presence versus absence of) negative affect, mostly in the context of being not-included or being excluded, whereas the positive orientation of inclusion is underrepresented. In order to measure social inclusion needs, we thus developed a set of new Need for Inclusion items, and we distinguished between the relational and the collective level of inclusion.

\section{Main findings}

The present Study 1 provided evidence of the reliability and factorial validity of our newly developed set of items. Specifically, we were able to show that the scales have sound psychometric properties in terms of internal consistency, and that they constitute distinct factors. Moreover, the proposed two-dimensional measure showed an adequate fit. In the second study, we showed that the Need for Inclusion scales are distinct from the Need to Belong Scale (Leary et. al., 2013; Schreindorfer \& Leary, 1996) as well as from two scales probing in the sense of belongingness. Moreover, both Relational and Collective Need for Inclusion positively contributed to sense of belongingness, whereas the Need to Belong scales showed negative relationships.

In Study 2, we performed further psychometric tests of the set of new items and we investigated the differential relationships of Relational and Collective Need for Inclusion and the Need to Belong Scale with a number of relevant target variables. With respect to the psychometric analyses, it was revealed that the two-dimensional structure was replicated, and test-retest reliability proved to be sufficient. Joint factor-analysis of the Need for Inclusion scales and Need to Belong, Relatedness Valuation, Relatedness Frustration, Relatedness Satisfaction, Collective Self-Esteem, and Group Identification also led to clear distinct, conceptual factors, as such showing the distinctiveness of the new Need for Inclusion scales. Importantly, both Relational and Collective Need for Inclusion independently contributed to higher levels of well-being in regression analyses, showing that inclusion needs at both levels of the self are associated with positive outcomes. These relationships confirm the theorybased hypotheses regarding belongingness and inclusion, which should clearly benefit the 
individual and increase his or her psychological health (Baumeister, 1991; Bolger et al., 2000; Spiegel et al., 1989; Tyler \& Lind, 1992; Valkenburg et al., 2006). Moreover, the Need for Inclusion scales were also positively associated with Relatedness Valuation and Relatedness Satisfaction. Such relationships would also be predicted based on SelfDetermination Theory (Deci \& Ryan, 2000; Sheldon \& Gunz, 2009), as the motivation to establish meaningful relationships is at least in part intrinsic (Lavigne et al., 2011), which leads to increased psychological well-being. Inclusion needs, both at the level of social relations and social groups, are beneficial to the well-being of the individual. Moreover, regression analyses revealed that Collective Need for Inclusion is strongly related to outcomes that are situated at the group or collective levels, such as in the case of collective self-esteem and social acceptance.

Importantly, the Need to Belong Scale (Leary et. al., 2013; Schreindorfer \& Leary, 1996) showed a reversed pattern of relationships with the well- and ill-being variables. The Need to Belong Scale consists of many items that refer to the negative affect people feel when being excluded. Not surprisingly, then, people who more strongly react to being shunned, rejected or ostracized, do not show high levels of well-being. Indeed, the Need to Belong Scale showed a positive relationship with negative feelings, thoughts and emotions, such as poor mental health, negative affect, and anxiety for close relationships. Moreover, the Need to Belong contributed positively to Relatedness Frustration. The present results are reminiscent of those reported by Lavigne et al. (2011). These authors reported that a growth orientation underlying the Need to Belong concept is positively related to well-being, whereas this orientation was virtually unrelated to the Need to Belong Scale. The deficit reduction orientation, however, showed a strong negative relationship with well-being as well as a positive relationship with the Need to Belong Scale. Although we took another approach than Lavigne et al. (2011) - we considered inclusion as a positive and wanted to study outcomes irrespective of whether growth or deficit reduction is the underlying goal - we were able to show that inclusion needs contribute to well-being, whereas the Need to Belong Scale was negatively related.

\section{Inclusion needs are prevalent and contribute to psychological well-being}

The Need for Inclusion is a positive variable. Many people aspire to being in the company of others and the more they do, the happier they are. This might seem a bit strange at first glance. Indeed, individuals who actively search for warmth, love, approval and support of others or who want to be included in social groups, in fact depend on these others, and this dependency may backfire if these others do not provide the anticipated benefits. 
Another way of stating this idea is that by having a focus on other people and on groups, one's well-being becomes contingent upon another actor or entity. The high prevalence of inclusion needs among humans as well as its positive effects can only be understood from the perspective that humans are true social animals.

A recurring finding in our two studies is that the mean level of Relational Need for Inclusion is generally high (above 4 on a 5-point scale), and higher than Collective Need for Inclusion and the Need to Belong scales, which show mean scores close to the theoretical midpoint of the scale. Given that inclusion needs are considered to be a universal human motivation that is observed among all cultures and human beings (Baumeister \& Leary, 1995; Fiske, 2004), high scores should in fact be expected. Such high scores reflect that the human Need for Inclusion is important. The finding that Collective Need for Inclusion is at a lower level compared to Relational Need for Inclusion, may be explained by the fact that we collected our data in the U.S., a Western country that has an individualistic orientation. In such individualist countries, people tend to de-emphasize the importance of group ties and affiliations to collectives (Triandis, 1995).

Importantly, however, culture does not seem to constitute a sound explanation for the relatively low scores obtained with the Need to Belong Scale (Leary et. al., 2013; Schreindorfer \& Leary, 1996). It is remarkable that people are generally unreactive to items that probe into what has been considered in literature as the most basic human drive (Fiske, 2004). However, the reason for this low mean score seems to reside in the content of the items themselves, which almost invariably fail to elicit high agreement. A closer look at each of the ten items included in the Need to Belong Scale even shows that most items yield a mean score close to the theoretical midpoint, in the range of 2.5 to 3.5 on a 5-point scale. The endorsement levels are only higher for the items "I need to feel that there are people I can turn to in times of need" (item $4, M=3.85$ ). and "I want other people to accept me" (item 5, $M=3.75)$.

It stands to reason that one cannot be blind for the negative consequences of basic human needs, and that some individuals are better equipped to cope with these adverse consequences than others. As is the case with many of our cherished needs, a strong striving to fulfill belongingness may lead to high expectations and positive feelings, but for those who are striving fulfillment the most, frustration of this need is especially aversive and leads to a host of negative reactions. This explains why the Need for Inclusion and Need to Belong scales show strong positive relationships. In the case of belongingness needs, reactions to inclusion and exclusion represent two different aspects. For this reason, the scales for 
Relational and Collective Need for Inclusion do not intend to replace the scale for Need to Belong constructed by Leary and his colleagues (Leary et. al., 2013; Schreindorfer \& Leary, 1996), but rather aim to complement it. In order to get a more correct and especially more complete image, it is recommended to use both scales for the study of belongingness in future research.

\section{Collective inclusion needs as a relevant variable for our understanding of the social group}

There is some tension between the conceptual and empirical levels of the work on belongingness needs. Need to Belong has been described as pertaining to the need to belong into a network of social relationships (Baumeister \& Leary, 1995) as well as to the need to be part of social groups (Leary et al., 2014). In many introductory texts of group processes, the Need to Belong is mentioned as a basic motivation underlying group formation (Fiske, 2004). In empirical terms, however, the Need to Belong scale has been predominantly investigated as a variable in the context of social relations and intra-group processes. We believe that the reason for this relative neglect of studies of belongingness needs in group level phenomena is quite straightforward: Even though its items do not actively describe a target as either other persons or social groups, the Need to Belong Scale has more face validity as an interpersonal measure and its items are more easily interpreted in terms of interpersonal relations.

We hope that the present work on the Collective Need for Inclusion scale will pave the path towards a better integration of this need in the study of group-level phenomena. In this context, it is important to delineate the Collective Need for Inclusion from other theoretical frameworks and variables. The first important distinction pertains to the idea that the Collective Need for Inclusion pertains to groups-in-general, whereas much theorizing on identification has been done within the context of particular groups. Social Categorization Theory (Turner \& Tajfel, 1986), for instance, holds that group categorization is imposed by the interaction between the context and an individual's perceptual readiness to perceive these particular groups. Group identification, then, is a process based on perceived in- and outgroup differences, and similarities within both these groups. This approach does not attest very well to the fact that some individuals are more "groupie" than others. In other words, these theories do not delve into the idea of a general inclination to identify, but rather present identification as a specific inclination towards one particular group. Especially if one seeks to investigate linkages between personality and group-related processes (which is a largely neglected area of research), it makes more sense to investigate measures of general group orientation than any orientation to specific groups. In addition, there is another difference 
between Need for Inclusion and Group Identification. Specifically the (Collective) Need for Inclusion constitutes a first step which involves the need to be included in a social group, whereas Group Identification occurs when people consider themselves to be part of the group, thus reflecting processes that are most often likely to take place at a later moment in time (but see self-anchoring and self-projection processes in group contexts; e.g. van Veelen, Otten, \& Hansen, 2013).

The finding that Collective Need for Inclusion contributes to well-being also corroborates the so-called 'social cure hypothesis' which holds that group identification can lead to higher levels of psychological and even physical well-being (e.g. Haslam, Jetten, Postmes, \& Haslam, 2009; Ysseldyk, McQuaid, McInnis, Anisman, \& Matheson, 2019). As a strong Collective Need for Inclusion is likely to motivate people to search for membership to and identify with social groups, they can be expected to reap the benefits of group membership and identification, which is, among others, an increased level of well-being. According to such an approach, sense of belongingness and group identification can be considered as outcomes of need satisfaction which, in turn, increases well-being. Or, put otherwise, an alternative interpretation of social cure is that it is obtained because of the satisfaction of inclusion needs.

The present results are also related to some recent work which integrates SelfDetermination Theory (Deci \& Ryan, 2000; Vansteenkiste et al., 2006) and Social Identity Theory (see Amiot, Sansfaçon, Louis, \& Yelle, 2012; Thomas, Amiot, Louis, \& Goddard, 2017; also see Kachanoff, Taylor, Caouette, Khullar, \& Wohl, 2019). According to this approach, people often act as group members and they can perceive their behavior as being collectively motivated, which has been coined as 'collective self-determination'. In keeping up with Self-Determination Theory, such group-level motivations can be either autonomous and self-determined, or not. The present approach resembles the work of Amiot and colleagues in some critical aspects, but shows some differences as well. Specifically, the Collective Need for Inclusion as presently studied should be considered as an antecedent of group membership, whereas the work of Amiot and colleagues often studied processes once membership is present (but, see Amiot, Terry, Wirawan, \& Grice, 2010, for a longitudinal design). Moreover, we do not make a distinction between needs that are self-determined or not. However, both these approaches have an important similarity at a theoretical level, arguing that concepts that are commonly used on an intra- or interpersonal level can be extended to the collective level, as such being informative for the study of collective processes (Vignoles et al., 2006).

This article is protected by copyright. All rights reserved 
Finally, another interesting finding pertains to the mediation effect of sense of belongingness in the relation between Collective Need for Inclusion and "collective" variables such as social trust, increased social identification, and collective self-esteem. Of special relevance is the relationship of the inclusion needs with social trust, which is an important asset for the creation of societal cohesion (Putnam, 2000). Societies could try to raise inclusion of their citizens, and especially minorities could profit from such an approach because the importance of psychological binding with the majority group (see Putnam, 2000). Procedural fairness is one possibility of an intervention strategy that promotes inclusion, because it flags to the individual that he or she belongs to the group (see De Cremer \& Tyler, 2005).

\section{Conclusion}

The newly developed Relational and Collective Need for Inclusion scales thus contribute to the explained variance in psychological well- and ill-being. People who have a need to have social relationships and who want to be included in groups show better psychological health. Although both these Need for Inclusion scales are positively related to the Need to Belong Scale (Leary et. al., 2013; Schreindorfer \& Leary, 1996), compared to the latter scale, they show a reversed pattern of relationships with well- and ill-being. 


\section{References}

Amiot, C. E., Sansfaçon, S., Louis, W. R., \& Yelle, M. (2012). Can intergroup behaviors be emitted out of self-determined reasons? Testing the role of group norms and behavioural congruence in the internalization of discrimination and parity behaviors. Personality and Social Psychology Bulletin, 38, 63-76. DOI: 10.1177/0146167211429804

Amiot, C. E., Terry, D. J., Wirawan, D., \& Grice, T. A. (2010). Changes in social identities over time: The role of coping and adaptation processes. British journal of social psychology, 49, 803-826. DOI: 10.1348/014466609X480624

Asparouhov, T., \& Muthén, B. (2009). Exploratory Structural Equation Modeling. Structural Equation Modeling: A Multidisciplinary Journal, 16, 397-438.

Banks, M. H., Clegg, C. W., Jackson, P. R., Kemp, N. J., Stafford, E. M., \& Wall, T. D. (1980). The use of the General Health Questionnaire as an indicator of mental health in occupational studies. Journal of Occupational Psychology, 53, 187-194. DOI: 10.1111/j.2044-8325.1980.tb00024.x

Baumeister, R. F. (1991). Meanings of life. New York: Guilford Press.

Baumeister, R. F., \& Leary, M. R. (1995). The need to belong: desire for interpersonal attachments as a fundamental human motivation. Psychological Bulletin, 117, 497-529. DOI: 10.1037/0033-2909.117.3.497

Bentler, P. M. (1990). Comparative fit indexes in structural models. Psychological Bulletin, 107, 238-246. DOI: 10.1037/0033-2909.107.2.238

Bentler, P. M. (1995). EQS structural equations program manual. Encino, CA: Multivariate Software, Inc.

Boateng, G. O., Neilands, T. B., Frongillo, E. A., Melgar-Quiñonez, H. R., \& Young, S. L. (2018). Best practices for developing and validating scales for health, social, and behavioral research: a primer. Frontiers in Public Health, 6, 1-18. DOI: 10.3389/fpubh.2018.00149

Bolger, N., Zuckerman, A., \& Kessler, R. C. (2000). Invisible support and adjustment to stress. Journal of Personality and Social Psychology, 79, 953-961. DOI: 10.1037/00223514.79.6.953

Brewer, M. B., \& Gardner, W. (1996). Who is this" We"? Levels of collective identity and self representations. Journal of Personality and Social Psychology, 71, 83-93. DOI: 10.1037/0022-3514.71.1.83 
Burns, N., Kinder, D., \& Rahn, W. (2000). Social trust and democratic politics. Report to the National Election Studies Board based on the 2000 NES Special Topic Pilot Study.

Chen, B., Vansteenkiste, M., Beyers, W., Boone, L., Deci, E. L., Van der Kaap-Deeder, J., ... \& Ryan, R. M. (2015). Basic psychological need satisfaction, need frustration, and need strength across four cultures. Motivation and Emotion, 39, 216-236. DOI: $10.1007 / \mathrm{s} 11031-014-9450-1$

Chen, F., Curran, P. J., Bollen, K. A., Kirby, J., \& Paxton, P. (2008). An empirical evaluation of the use of fixed cutoff points in RMSEA test statistic in structural equation models. Sociological methods \& research, 36, 462-494. DOI: 10.1177/0049124108314720

Clark, L. A., \& Watson, D. (1995). Constructing validity: Basic issues in objective scale development. Psychological assessment, 7(3), 309-319. DOI: 10.1037/10403590.7.3.309

Cohen, J. (1988). Statistical power analysis for the behavioral sciences (2nd ed.). Hillsdale, NJ: Erlbaum

Comrey, A. L., \& Lee, H. B. (2013). A first course in factor analysis. Hove, UK: Psychology press. DOI: $10.4324 / 9781315827506$

Deci, E. L., \& Ryan, R. M. (2000). The "what" and "why” of goal pursuits: Human needs and the self-determination of behavior. Psychological Inquiry, 11, 227-268. DOI: 10.1207/S15327965PLI1104_01

De Cremer, D., \& Leonardelli, G. J. (2003). Cooperation in social dilemmas and the need to belong: The moderating effect of group size. Group Dynamics: Theory, Research, and Practice, 7, 168-174. DOI: 10.1037/1089-2699.7.2.168

De Cremer, D., \& Tyler, T. R. (2005). Managing group behavior: The interplay between procedural justice, sense of self, and cooperation. Advances in Experimental Social Psychology, 37, 151-218. DOI: 10.1016/S0065-2601(05)37003-1

Diener, E. D., Emmons, R. A., Larsen, R. J., \& Griffin, S. (1985). The satisfaction with life scale. Journal of Personality Assessment, 49, 71-75. DOI: 10.1207/s15327752jpa4901_13

Dovidio, J. F., Gaertner, S. L., Niemann, Y. F., \& Snider, K. (2001). Racial, ethnic, and cultural differences in responding to distinctiveness and discrimination on campus: Stigma and common group identity. Journal of Social Issues, 57, 167-188. DOI: 10.1111/0022-4537.00207

Fiske, S. T. (2004). Social Beings: Core Motives in Social Psychology $\left(2^{\text {nd }}\right.$ Ed.). New York: Wiley \& Sons. 
Forsyth, D. R. (1999). Group Dynamics (Third Edition). Belmont: Wadsworth Publishing Company.

Fraley, R. C., Heffernan, M. E., Vicary, A. M., \& Brumbaugh, C. C. (2011). The experiences in close relationships - Relationship Structures Questionnaire: A method for assessing attachment orientations across relationships. Psychological Assessment, 23, 615-625. DOI: $10.1037 / \mathrm{a} 0022898$

French, E. G., \& Chadwick, I. (1956). Some characteristics in affiliation motivation. The Journal of Abnormal and Social Psychology, 52(3), 296-300. DOI: 10.1037/h0045251

Gable, S. L. (2006). Approach and avoidance social motives and goals. Journal of Personality, 74, 175-222. DOI: 10.1111/j.1467-6494.2005.00373.x

Gray, J. A. (1987). The psychology of fear and stress (2nd ed.). New York: Cambridge University Press.

Hagerty, B. M., \& Patusky, K. (1995). Developing a measure of sense of belonging. Nursing Research, 44, 9-13. DOI: 10.1097/00006199-199501000-00003

Haslam, S. A., Jetten, J., Postmes, T., and Haslam, C. (2009). Social identity, health and wellbeing An emerging agenda for applied psychology. Applied Psychology An International Review, 58, 1-23. DOI: 10.1111/j.1464-0597.2008.00379.x

Heene, M., Hilbert, S., Draxler, C., Ziegler, M., \& Bühner, M. (2011). Masking misfit in confirmatory factor analysis by increasing unique variances: a cautionary note on the usefulness of cutoff values of fit indices. Psychological methods, 16, 319. DOI: $10.1037 / \mathrm{a} 0024917$

Hornsey, M. J., \& Jetten, J. (2004). The individual within the group: Balancing the need to belong with the need to be different. Personality and Social Psychology Review, 8, 248264. DOI: $10.1207 / \mathrm{s} 15327957$ pspr0803_2

Hu, L. T., \& Bentler, P. M. (1998). Fit indices in covariance structure modeling: Sensitivity to underparameterized model misspecification. Psychological Methods, 3, 424-453. DOI:

Hu, L. T., \& Bentler, P. M. (1999). Cut-off criteria for fit indexes in covariance structure analysis: conventional criteria versus new alternatives. Structural Equation Modeling, 6, 1-55. DOI: 10.1080/10705519909540118

Johnson, R. E., Selenta, C., \& Lord, R. G. (2006). When organizational justice and the selfconcept meet: Consequences for the organization and its members. Organizational Behavior and Human Decision Processes, 99, 175-201. DOI: 10.1016/j.obhdp.2005.07.005

This article is protected by copyright. All rights reserved 
Jorgensen, T. D., Pornprasertmanit, S., Schoemann, A. M., \& Rosseel, Y. (2018). semTools: Useful tools for structural equation modeling. R package version 0.5-1.

Kachanoff, F. J.; Taylor, D. M., Caouette, J. Khullar, T. H., \& Wohl, M. J. A. (2019). The chains on all my people are the chains on me: Restrictions to collective autonomy undermine the personal autonomy and psychological well-being of group members. Journal of Personality and Social Psychology, 116, 141-165. DOI: 10.1037/pspp0000177

Keyes, C. L. M. (1998). Social well-being. Social Psychology Quarterly, 61, 121-140. DOI: $10.2307 / 2787065$

Kline, R. B. (2015). Principles and practice of structural equation modeling. Guilford publications.

Kramer, R. M. (1993). Cooperation and organizational identification. J. K. Murnighan, ed. Social Psychology in Organizations: Advances in Theory and Research. Prentice-Hall, Englewood Cliffs, NJ, 244-268.

Kramer, R. M., Hanna, B. A., Su, S., \& Wei, J. (2001). Collective identity, collective trust, and social capital: Linking group identification and group cooperation. Groups at work: Theory and Research, 173-196. Mahwah, NJ: Erlbaum.

Lavigne, G. L., Vallerand, R. J., \& Crevier-Braud, L. (2011). The fundamental need to belong: On the distinction between growth and deficit-reduction orientations. Personality and Social Psychology Bulletin, 37, 1185-1201. DOI: $10.1177 / 0146167211405995$

Leach, C. W., Van Zomeren, M., Zebel, S., Vliek, M. L., Pennekamp, S. F., Doosje, B., Ouwerkerk, J. W., \& Spears, R. (2008). Group-level self-definition and selfinvestment: a hierarchical (multicomponent) model of in-group identification. Journal of Personality and Social Psychology, 95, 144-165. DOI: 10.1037/00223514.95.1.144

Leary, M. R., Kelly, K. M., Cottrell, C. A., \& Schreindorfer, L. S. (2013). Construct validity of the need to belong scale: Mapping the nomological network. Journal of Personality Assessment, 95, 610-624. DOI: 10.1080/00223891.2013.819511

Levine, J. M., \& Kerr, N. L. (2007). Inclusion and exclusion: Implications for group processes. In A. W. Kruglanski \& E. T. Higgins (Eds.), Social Psychology: Handbook of basic principles (2nd ed., pp. 759 - 784). New York: Guilford Press. 
Lord, R. G., Brown, D. J., \& Freiberg, S. J. (1999). Understanding the dynamics of leadership: The role of follower self-concepts in the leader/follower relationship. Organizational behavior and human decision processes, 78, 167-203. DOI: 10.1006/obhd.1999.2832

Loveland, K. E., Smeesters, D., \& Mandel, N. (2010). Still preoccupied with 1995: The need to belong and preference for nostalgic products. Journal of Consumer Research, 37, 393408. DOI: $10.1086 / 653043$

Luhtanen, R., \& Crocker, J. (1992). A collective self-esteem scale: Self-evaluation of one's social identity. Personality and Social Psychology Bulletin, 18, 302-318. DOI: $10.1177 / 0146167292183006$

Lyubomirsky, S., \& Lepper, H. S. (1999). A measure of subjective happiness: Preliminary reliability and construct validation. Social Indicators Research, 46, 137-155.

MacCallum, R. C., \& Austin, J. T. (2000). Applications of structural equation modeling in psychological research. Annual Review of Psychology, 51, 201-226. DOI:

10.1146/annurev.psych.51.1.201

Malone, G. P., Pillow, D. R., \& Osman, A. (2012). The general belongingness scale (GBS): Assessing achieved belongingness. Personality and Individual Differences, 52, 311316. DOI: 10.1016/j.paid.2011.10.027

Marsh, H. W., Morin, A. J., Parker, P. D., \& Kaur, G. (2014). Exploratory structural equation modeling: An integration of the best features of exploratory and confirmatory factor analysis. Annual Review of Clinical Psychology, 10, 85-110. DOI: 10.1146/annurevclinpsy-032813-153700

Mellor, D., Stokes, M., Firth, L., Hayashi, Y., \& Cummins, R. (2008). Need for belonging, relationship satisfaction, loneliness, and life satisfaction. Personality and Individual Differences, 45, 213-218. DOI: 10.1016/j.paid.2008.03.020

Muthén, L. K., \& Muthén, B. O. (1998-2015). Mplus User's Guide [Seventh Edition]. Los Angeles, CA.

Phinney, J. S. (1992). The multigroup ethnic identity measure: A new scale for use with diverse groups. Journal of Adolescent Research, 7, 156-176. DOI: 10.1177/074355489272003

Pickett, C. L., Gardner, W. L., \& Knowles, M. (2004). Getting a cue: The need to belong and enhanced sensitivity to social cues. Personality and Social Psychology Bulletin, 30, 1095-1107. DOI: 10.1177/0146167203262085

Putnam, R. D. (2000). Bowling Alone. The Collapse and Revival of American Community. New York: Simon \& Schuster.

This article is protected by copyright. All rights reserved 
Robins, R. W., Hendin, H. M., \& Trzesniewski, K. H. (2001). Measuring global self-esteem: Construct validation of a single-item measure and the Rosenberg Self-Esteem Scale. Personality and Social Psychology Bulletin, 27, 151-161. DOI: $10.1177 / 0146167201272002$

Roets, A., \& Van Hiel, A. (2008). Why some hate to dilly-dally and others do not: The arousal-invoking capacity of decision-making for low-and high-scoring need for closure individuals. Social Cognition, 26, 333-346. DOI: 10.1521/soco.2008.26.3.333

Schönbrodt, F. D., \& Gerstenberg, F. X. (2012). An IRT analysis of motive questionnaires: The unified motive scales. Journal of Research in Personality, 46(6), 725-742. DOI: 10.1016/j.jrp.2012.08.010

Schreindorfer, L., \& Leary, M. (1996). Seeking acceptance versus avoiding rejection: Differential effects on emotion and behaviour. Paper presented at the meeting of the Southeastern Psychological Association, Norfolk, VA.

Schumacker, R. E., \& Lomax, R. G. (2004). A beginner's guide to structural equation modeling. Mahwah, NJ: Psychology Press.

Sedikides, C. (2001). Individual Self, Relational Self, and Collective Self: Partners, Opponents, or Strangers? In C. Sedikides \& M. B. Brewer (Eds.), Individual self, relational self, collective self (pp. 1-4). Philadelphia, PA: Psychology Press.

Sedikides, C., Hart, C. M., \& De Cremer, D. (2008). The self in procedural fairness. Social and Personality Psychology Compass, 2, 2107-2124. DOI: 10.1111/j.17519004.2008.00156.x

Sheldon, K. M., \& Bettencourt, B. (2002). Psychological need-satisfaction and subjective well-being within social groups. British Journal of Social Psychology, 41, 25-38. DOI: $10.1348 / 014466602165036$

Sheldon, K. M., Gunz, A. (2009). Psychological needs as basic motives, not just experiential requirements. Journal of Personality, 77, 1467-1492. DOI: 10.1111/j.14676494.2009.00589.x

Sokolowski, K. (2008). Social bonding: Affiliation motivation and intimacy motivation. In J. Heckhausen \& H. Heckhausen (Eds.), Motivation and action (2nd ed.). (pp. 184-201). New York, NY US: Cambridge University Press.

Spiegel, D., Kraemer, H., Bloom, J., \& Gottheil, E. (1989). Effect of psychosocial treatment on survival of patients with metastatic breast cancer. The Lancet, 334, 888-891. DOI: 10.1016/S0140-6736(89)91551-1 
Steiger, J. H., \& Lind, J. C. (1980, May). Statistically based tests for the number of factors. Paper presented at the annual spring meeting of the psychometric society, Iowa City, IA.

Thomas, E. F., Amiot, C. E., Louis, W. R. and Goddard, A. (2017) Collective Self-

Determination: How the Agent of Help Promotes Pride, Well-Being, and Support for Intergroup Helping. Personality and Social Psychology Bulletin, 43, 662-677. DOI: $10.1177 / 0146167217695553$

Triandis, H. C. (1995). Individualism \& collectivism. Boulder, CO: Westview press.

Turner, J. C., Hogg, M. A., Oakes, P. J., Reicher, S. D., \& Wetherell, M. S. (1987). Rediscovering the social group: A self-categorization theory. Oxford: Basil Blackwell.

Turner, J. C., \& Tajfel, H. (1986). The social identity theory of intergroup behavior. In S. Worchel \& WG Austin (Eds.), Psychology of intergroup relations, (pp.7-24). Chicago: Nelson-Hall.

Tyler, T. R., \& Lind, E. A. (1992). A relational model of authority in groups. Advances in Experimental Social Psychology, 25, 115-191. DOI: 10.1016/S0065-2601(08)60283-X

Van den Broeck, A., Vansteenkiste, M., De Witte, H., Soenens, B., \& Lens, W. (2010). Capturing autonomy, competence, and relatedness at work: Construction and initial validation of the Work-related Basic Need Satisfaction scale. Journal of Occupational and Organizational Psychology, 83, 981-1002. DOI: 10.1348/096317909X481382

Valkenburg, P. M., Peter, J., \& Schouten, A. P. (2006). Friend networking sites and their relationship to adolescents' well-being and social self-esteem. CyberPsychology \& Behavior, 9, 584-590. DOI: 10.1089/cpb.2006.9.584

Van Hiel, A., De Cremer, D., \& Stouten, J. (2008). The personality basis of justice: The five-factor model as an integrative model of personality and procedural fairness effects on cooperation. European Journal of Personality, 22, 519-539. DOI: 10.1002/per.691

Vansteenkiste, M., Lens, W., Soenens, B., \& Luyckx, K. (2006). Autonomy and relatedness among Chinese sojourners and applicants: Conflictual or independent predictors of wellbeing and adjustment? Motivation and Emotion, 30, 273-282. DOI: 10.1007/s11031006-9041-x

van Veelen, R., Otten, S., \& Hansen, N. (2013). Social identification when an in-group identity is unclear: The role of self-anchoring and self-stereotyping. British Journal of Social Psychology, 52(3), 543-562. DOI:10.1111/j.2044-8309.2012.02110.x

This article is protected by copyright. All rights reserved 
Vignoles, V. L., Regalia, C., Manzi, C., Golledge, J., \& Scabini, E. (2006), Beyond SelfEsteem: Influence of Multiple Motives on Identity Construction. Journal of Personality and Social Psychology, 90, 308-333. DOI: 10.1037/0022-3514.90.2.308

Watson, D., Clark, L. A., \& Tellegen, A. (1988). Development and validation of brief measures of positive and negative affect: the PANAS scales. Journal of Personality and Social Psychology, 54, 1063-1070. DOI: 10.1037/0022-3514.54.6.1063

Wiesner, M., \& Schanding, G. T. (2013). Exploratory structural equation modeling, bifactor models, and standard confirmatory factor analysis models: Application to the BASC-2 behavioral and emotional screening system teacher form. Journal of School Psychology, 51, 751-763. DOI: 10.1016/j.jsp.2013.09.001

Williams, K. D., Forgas, J. P., \& Von Hippel, W. (Eds.). (2005). The social outcast: Ostracism, social exclusion, rejection, and bullying. New York: Psychology Press. Ysseldyk R, McQuaid R. J., McInnis O. A., Anisman H., \& Matheson K. (2018). The ties that bind: Ingroup ties are linked with diminished inflammatory immune responses and fewer mental health symptoms through less rumination. PLoS ONE, 13(4):e0195237.

Williams, B., Onsman, A., \& Brown, T. (2010). Exploratory factor analysis: A five-step guide for novices. Australasian Journal of Paramedicine, 8(3). DOI: 10.33151/ajp.8.3.93

Yong, A. G., \& Pearce, S. (2013). A beginner's guide to factor analysis: Focusing on exploratory factor analysis. Tutorials in quantitative methods for psychology, 9(2), 79-94. DOI: 10.20982/tqmp.09.2.p079 


\section{Footnotes}

${ }^{1}$ In the first version of our manuscript, we had developed an initial item set for Relational and Collective Inclusion, which was criticized in the initial phase of the review process. Specifically, those previous items sometimes included content that tapped into need frustration or need satisfaction, which the Reviewers rightfully have identified as a problem. We thus generated a new set of items, which have been included in the current version of the manuscript. The raw data pertaining to the initial item set can be found on https://osf.io/bdycm/. Analyses of this item set yield similar results as those currently presented.

${ }^{2}$ Given that in subsequent regression analyses we tested for the unique contribution of Need to Belong and Need for Inclusion, we decided not to omit any item. The inclusion of all items constitutes the more conservative test of each of these scales' unique contributions. 
Table 1

Descriptive statistics of sample Study 1

\begin{tabular}{|c|c|c|c|c|c|}
\hline \multicolumn{2}{|c|}{ Ethnic background } & \multicolumn{2}{|c|}{ Education level } & \multicolumn{2}{|c|}{ Annual family income } \\
\hline Category & Percentage & Category & Percentage & Category & Percentage \\
\hline White & $98.9 \%$ & $\begin{array}{l}\text { Did not } \\
\text { graduate }\end{array}$ & $1.6 \%$ & $0 \$-50,000 \$$ & $48.7 \%$ \\
\hline Hispanic & $0.5 \%$ & High school & $43.9 \%$ & $\begin{array}{l}50,000 \$- \\
100,000 \$\end{array}$ & $38.5 \%$ \\
\hline Native & $0.5 \%$ & $\begin{array}{c}\text { Bachelor's } \\
\text { degree }\end{array}$ & $40.1 \%$ & $\begin{array}{c}100,000 \$- \\
150,000 \$\end{array}$ & $10.2 \%$ \\
\hline & & $\begin{array}{l}\text { Master's } \\
\text { degree }\end{array}$ & $12.8 \%$ & $\begin{array}{c}150,000 \$- \\
200,000 \$\end{array}$ & $1.1 \%$ \\
\hline & & $\begin{array}{c}\text { Phd or } \\
\text { equivalent }\end{array}$ & $1.6 \%$ & $\begin{array}{c}200,000 \$ \text { or } \\
\text { more }\end{array}$ & $1.6 \%$ \\
\hline
\end{tabular}


Table 2

ESEM - Factor loadings of items for the Relational NI and Collective NI scales (Study 1)

\begin{tabular}{|c|c|c|}
\hline Item & I & II \\
\hline \multicolumn{3}{|l|}{ Relational NI } \\
\hline I would like to spend time with people close to me & .79 & -.08 \\
\hline I need interactions with people close to me & .72 & .12 \\
\hline I have a strong desire to be in contact with people close to me & .77 & .06 \\
\hline It is important for me that I am accepted by the persons closest to me & .72 & .02 \\
\hline It is important to me that people close to me care about me & .84 & .00 \\
\hline I need to feel connected to people close to me & .81 & -.01 \\
\hline I want to experience the warmth of people close to me & .81 & .04 \\
\hline I would feel pleased when people close to me appreciate me & .74 & .04 \\
\hline I would rather be alone than with significant others $(\mathrm{R})$ & .63 & -.12 \\
\hline I do not need to be loved by friends and family (R) & .76 & .00 \\
\hline \multicolumn{3}{|l|}{ Collective NI } \\
\hline I want to belong to a group & .13 & .80 \\
\hline Being a member of social groups is necessary to me & .06 & .82 \\
\hline I think groups do not matter much in my life (R) & .00 & .76 \\
\hline I do not want to belong to groups (R) & .09 & .71 \\
\hline I need to belong to groups to have some guidance in life & -.04 & .66 \\
\hline Being part of a group is important to me & -.01 & .91 \\
\hline I do not need groups to feel good about myself (R) & -.15 & .72 \\
\hline I need to feel connected to groups & -.07 & .83 \\
\hline Not being included in groups would make me feel bad & .06 & .69 \\
\hline Groups can be my safe haven & .04 & .72 \\
\hline
\end{tabular}

Note. (R) denotes items reversed so that higher scores indicate higher NI.

This article is protected by copyright. All rights reserved 
Table 3

Descriptive statistics of sample Study 2

\begin{tabular}{|c|c|c|c|c|c|}
\hline \multicolumn{2}{|c|}{ Ethnic background } & \multicolumn{2}{|c|}{ Education level } & \multicolumn{2}{|c|}{ Annual family income } \\
\hline Category & Percentage & Category & Percentage & Category & Percentage \\
\hline White & $89.3 \%$ & $\begin{array}{l}\text { Did not } \\
\text { graduate }\end{array}$ & $4.5 \%$ & $0 \$-50,000 \$$ & $61.2 \%$ \\
\hline Hispanic & $5 \%$ & High school & $43 \%$ & $\begin{array}{c}50,000 \$- \\
100,000 \$\end{array}$ & $29.8 \%$ \\
\hline Asian & $2.9 \%$ & $\begin{array}{c}\text { Bachelor's } \\
\text { degree }\end{array}$ & $38 \%$ & $\begin{array}{c}100,000 \$- \\
150,000 \$\end{array}$ & $7.9 \%$ \\
\hline Black & $1.7 \%$ & $\begin{array}{l}\text { Master's } \\
\text { degree }\end{array}$ & $12.4 \%$ & $\begin{array}{c}150,000 \$- \\
200,000 \$\end{array}$ & $0.8 \%$ \\
\hline Native & $1.2 \%$ & $\begin{array}{c}\text { Phd or } \\
\text { equivalent }\end{array}$ & $2.1 \%$ & $\begin{array}{c}200,000 \$ \text { or } \\
\text { more }\end{array}$ & $0.4 \%$ \\
\hline
\end{tabular}

This article is protected by copyright. All rights reserved 
Table 4

Pearson correlations of scores on Need for Inclusion scales and Need to Belong, and outcome variables (Study 2)

Outcome variables Need scales

Subjective Happiness

\begin{tabular}{ccc}
\hline Relational NI & Collective NI & NTB scale \\
\hline .06 & .02 & $-.20^{* *}$ \\
.13 & $.16^{*}$ & -.06 \\
.06 & .05 & $-.20^{* *}$ \\
-.04 & .03 & $-.29^{* * *}$
\end{tabular}

Poor mental health

$-.03$

.03

$.25^{* * *}$

Negative Affect

$-.02$

.09

$.28^{* * *}$

ECR Anxiety

.10

$.18^{* *}$

$.47^{* * *}$

ECR Avoidance

$-.36^{* * *}$

$-.17^{* *}$

$-.17^{* * * *}$

Social trust

$.21^{* * *}$

$.25^{* * * *}$

$.15^{*}$

Social acceptance

$.18^{* * *}$

$.24^{* * *}$

.10

Group Identification

$.32^{* * *}$

$.49^{* * *}$

$.16^{*}$

Collective self-esteem

$.28^{* * *}$

$.30^{* * *}$

$-.02$

Relatedness needs

$.23^{* * *}$

$.37^{* * *}$

$-.00$

Relatedness frustration

$-.21^{* *}$

$-.04$

$.18^{* * *}$

Relatedness satisfaction

$.40^{* * * *}$

$.24^{* * *}$

.00

Note: ${ }^{*}: p<.05 ;{ }^{* *}: p<.01 ;{ }^{* * *}: p<.001$ 
Table 5

Regression analyses of Need for Inclusion and Need to Belong scales on target variables (Study 2)

\begin{tabular}{lccccc}
\hline \multirow{2}{*}{ Outcome variables } & \multicolumn{5}{c}{ Need scales } \\
\cline { 2 - 4 } & Rel. NI & Coll. NI & NTB scale & \\
\cline { 2 - 4 }$R^{2}$ Adj. (\%) & $F$ \\
\hline Subj. Happiness & $\beta$ & $\beta$ & $\beta$ & 9.0 & $8.93^{* * * *}$ \\
Subj. Well-Being & $.27^{* * * *}$ & .13 & $-.43^{* * *}$ & & \\
Positive Affect & $.23^{* *}$ & $.24^{* * *}$ & $-.33^{* * *}$ & 7.6 & $7.95^{* * * *}$ \\
& $.27^{* * *}$ & $.18^{*}$ & $-.45^{* * *}$ & 10.2 & $10.17^{* * *}$
\end{tabular}

This article is protected by copyright. All rights reserved 
Self-esteem

$$
.19^{* * *}
$$

$.23^{* * *}$

$-.52^{* * * *}$

14.1

$14.22^{* * *}$

Poor mental health

$$
-.27^{* * *}
$$

$-.10$

$.47^{* * *}$

11.0

$10.98^{* * *}$

Negative Affect

$-.30^{* * *}$

$-.04$

$.49^{* * *}$

13.1

$13.06^{* * *}$

ECR Avoidance

$-.41^{* * *}$

$-.08$

.12

12.9

$12.90^{* * * *}$

ECR Anxiety

$-.28^{* * * *}$

$-.05$

$.66^{* * *}$

26.0

$29.16^{* * *}$

Social trust

$$
.17^{*}
$$

$.22^{* *}$

$-.07$

6.9

$6.99^{* * *}$

Social acceptance

$.16^{*}$

$.23^{* *}$

$-.12$

6.1

$6.23^{* * *}$

Collective self-esteem

$.42^{* * *} \quad .38^{* * *}$

$-.47^{* * * *}$

23.2

$25.32^{* * * *}$

Group Identification

$.28^{* * *}$

$.53^{* * *}$

$-.29^{* * * *}$

29.7

$34.99^{* * *}$

Relatedness needs

$$
.31^{* * *}
$$

$.47^{* * *}$

$-.43^{* * * *}$

23.7

$25.94^{* * *}$

Relatedness frustration

$-.48^{* * *}$

$-.13^{*}$

$.54^{* * *}$

19.0

$19.95^{* * *}$

Relatedness satisfaction $\quad .59^{* * * *}$

$.27^{* * *}$

$-.49^{* * *}$

28.7

$33.35^{* * *}$ 
Table 6

Unstandardized coefficients from mediation analyses (Study 2)

\begin{tabular}{|c|c|c|c|}
\hline & Relational NI & Collective NI & NTB scale \\
\hline Subjective & Total: .09 & Total: .02 & Total: $\mathbf{- . 2 6}{ }^{* * *}$ \\
\hline \multirow[t]{3}{*}{ Happiness } & Direct:. $\mathbf{4 1} 1^{* * *}$ & Direct: .15 & Direct:.$- .57^{* * *}$ \\
\hline & Indirect via Coll. NI: .08 & Indirect via Rel. NI: .12**** & Indirect via Coll. NI: .09 \\
\hline & Indirect via NTB:.$- \mathbf{4 0}{ }^{* * *}$ & Indirect via NTB: $\mathbf{- . 2 4 ^ { * * * }}$ & Indirect via Rel. NI: .22 ${ }^{* * * *}$ \\
\hline Subjective & Total: .18 & Total: .17* & Total: -.08 \\
\hline \multirow[t]{3}{*}{ Well-Being } & Direct:. $\mathbf{3 3}^{* *}$ & Direct: $.25^{* * *}$ & Direct:.$- .41^{* * * *}$ \\
\hline & Indirect via Coll. NI: .14 ${ }^{* * *}$ & Indirect via Rel. NI: .09** & Indirect via Coll. NI: .16 \\
\hline & Indirect via NTB:.$- .29^{* * *}$ & Indirect via NTB:.$- .18^{* * *}$ & Indirect via Rel. NI: .18 \\
\hline Positive & Total: .07 & Total: .04 & Total: $\mathbf{- . 2 0}{ }^{* * *}$ \\
\hline \multirow[t]{3}{*}{ Affect } & Direct: $.31^{* * *}$ & Direct: . $\mathbf{1 5}^{*}$ & Direct: $\mathbf{- . 4 6 ^ { * * * }}$ \\
\hline & Indirect via Coll. NI: .08* & Indirect via Rel. NI: .09**** & Indirect via Coll. NI: .09* \\
\hline & Indirect via NTB: $-.32^{* * *}$ & Indirect via NTB: $\mathbf{- . 2 0}{ }^{* * *}$ & Indirect via Rel. NI: .16 \\
\hline Self- & Total: - .07 & Total: .04 & Total: $\mathbf{- . 4 5} \mathbf{5}^{* * *}$ \\
\hline \multirow[t]{3}{*}{ esteem } & Direct:. $\mathbf{3 4}{ }^{* *}$ & Direct:. $\mathbf{3 0}^{* * *}$ & Direct: $-.82^{* * *}$ \\
\hline & Indirect via Coll.NI: .16 & Indirect via Rel. NI: .10* & Indirect via Coll. NI: .19**** \\
\hline & Indirect via NTB: $-.56^{* * *}$ & Indirect via NTB:.$- .35^{* * * *}$ & Indirect via Rel. NI: .18** \\
\hline Poor & Total: -..03 & Total: .03 & Total: .29 ${ }^{* * *}$ \\
\hline Mental & Direct:.$- .36^{* * *}$ & Direct:-.10 & Direct: $.55^{* * *}$ \\
\hline \multirow[t]{2}{*}{ Health } & Indirect via Coll. NI: -.05 & Indirect via Rel.NI:.$- .10 * * * *$ & Indirect via Coll. NI: -.06 \\
\hline & Indirect via NTB: $\mathbf{3 8}^{* * *}$ & Indirect via NTB: $.23^{* * *}$ & Indirect via Rel. NI: $\mathbf{- . 1 9}$ \\
\hline Negative & Total: -.03 & Total: .14 & Total:. $\mathbf{3 2}{ }^{* * *}$ \\
\hline \multirow[t]{3}{*}{ Affect } & Direct:.$- .39^{* * * *}$ & Direct: -.02 & Direct: $\mathbf{5 5}^{* * *}$ \\
\hline & Indirect via Coll. NI: -.02 & Indirect via Rel.NI: -.13${ }^{* * *}$ & Indirect via Coll. NI: -.02 \\
\hline & Indirect via NTB:. $\mathbf{3 8}^{* * *}$ & Indirect via NTB: .28 ${ }^{* * *}$ & Indirect via Rel. NI: $-.21^{* * *}$ \\
\hline
\end{tabular}


ECR

Avoidance

ECR

Anxiety

Relatedness

Valuation

Need

Frustration

Need

Satisfaction

Social Trust

Social
Total: $\mathbf{- . 4 7 ^ { * * * * }}$

Direct:.$- .52^{* * * *}$

Indirect via Coll. NI: -.04

Indirect via NTB: .10

Total: .17

Direct:.$- \mathbf{4 6}{ }^{* * * *}$

Indirect via Coll. NI: -.03

Indirect via NTB: .66 ${ }^{* * *}$

Total: . .34****

Direct: .45 ${ }^{\text {**** }}$

Indirect via Coll. NI:..28**

Indirect via NTB: $-\mathbf{. 3 8}{ }^{* * *}$

Total: $\mathbf{- . 3 1}^{* *}$

Direct: $-.3^{* * * *}$

Indirect via Coll. NI: -.08

Indirect via NTB: .50***

Total: .54****

Direct: .80****

Indirect via Coll. NI:.14**

Indirect via NTB:.$- .41^{* * * *}$

Total:.22***

Direct: .18*

Indirect via Coll. NI: .09***

Indirect via NTB: -.04
Total: -.16***

Direct: -.07

Indirect via Rel.NI: -.15 ${ }^{* * * *}$

Indirect via NTB: .07

Total: . .22****

Direct: -.06

Indirect via Rel.NI: -..13 ${ }^{* * *}$

Indirect via NTB: .41 ${ }^{* * *}$

Total: .40****

Direct:.51 $1^{* * *}$

Indirect via Rel.NI: .13**

Indirect via NTB: $-\mathbf{. 2 4 * * *}$

Total: -.04

Direct: -.14*

Indirect via Rel.NI: -.21***

Indirect via NTB: ..31***

Total:.24*****

Direct:.26****

Indirect via Rel.NI: .23****

Indirect via NTB: $-.25^{* * * *}$

Total: .19****

Direct: . $\mathbf{1 7}^{\text {****}}$

Indirect via Rel. NI: .05*

Indirect via NTB: -.03
Total: $\mathbf{- . 1 9 * * *}$

Direct: .14

Indirect via Coll. NI: -.05

Indirect via Rel. NI: -.28***

Total: .68 ${ }^{* * *}$

Direct: .96****

Indirect via Coll. NI: -.04

Indirect via Rel. NI: $-.25^{* * *}$

Total: -.01

Direct: $-\mathbf{. 5 6}{ }^{* * *}$

Indirect via Coll. NI:.32****

Indirect via Rel. NI:.24****

Total: . .24***

Direct: . $72^{* * *}$

Indirect via Coll. NI: -.09

Indirect via Rel. NI: -..39****

Total: -.01

Direct: $-\mathbf{. 5 9}$ **** $^{\text {* }}$

Indirect via Coll. NI:.16***

Indirect via Rel. NI:.43 ${ }^{* * *}$

Total: .14*

Direct: -.06

Indirect via Coll. NI: .11 ${ }^{\text {***** }}$

Indirect via Rel. NI: .09*

This article is protected by copyright. All rights reserved 
Acceptance

\author{
Direct: .19* \\ Indirect via Coll. NI: .11 ${ }^{* * * *}$ \\ Indirect via NTB: -.08
}

Total: $.27^{* * *}$

Direct: .39***

Indirect via Coll.NI: .14

Indirect via NTB: $-.26^{* * *}$

Total: . $\mathbf{3 1}{ }^{* * *}$

Direct: .26 ${ }^{* * * *}$

Indirect via Coll.NI: .22 ${ }^{* * *}$

Indirect via NTB:-.17 $7^{* * *}$
Direct: .20***

Indirect via Rel. NI: .05*

Indirect via NTB: -.05

Total: .23 ${ }^{* * *}$

Direct: .29****

Indirect via Rel. NI: .11 ${ }^{\text {***** }}$

Indirect via NTB: $-.16^{* * *}$

Total: .43 ${ }^{* * *}$

Direct: .46***

Indirect via Rel. NI: .07****

Indirect via NTB:.$- \mathbf{1 0}^{* * *}$
Direct: $-.12^{* * * *}$

Indirect via Coll. NI: .12***

Indirect via Rel. NI: .10*

Total: -.03

Direct: $-.41^{* * * *}$

Indirect via Coll. NI: .16

Indirect via Rel. NI: .21 ${ }^{* * *}$

Total: $.15^{* *}$

Direct: $-.25^{* * *}$

Indirect via Coll. NI: .26 ${ }^{* * *}$

Indirect via Rel. NI: .14**

Note. ${ }^{*}: p<.05 ;{ }^{* *}: p<.01{ }^{* * *}: p<.001$. Figures in bold face indicate significant direct and indirect effects with an opposite sign. $\mathrm{NI}=$ Need for Inclusion; NTB $=$ Need to Belong. 